\title{
A Surgical Team Simulation to Improve Teamwork and Communication across Two Continents: ViSIOT'T Proof-of- Concept Study
}

Sharon Marie Weldon PhD ${ }^{a, b, c}$, Terhi Korkiakangas $\mathrm{PhD}^{\mathrm{c}}{ }^{\mathrm{c}}$, Jennifer Calzada MPH ${ }^{\mathrm{f}}$, James R. Korndorffer Jr MD MHPE ${ }^{g}$, Roger L. Kneebone $\mathrm{PhD}^{\mathrm{c}, \mathrm{e}}$.

a University of Greenwich, Faculty of Health and Education, Southwood Site, Avery Hill Rd, Eltham, London, UK. Telephone: +44(0)2083319705 | E-mail: S.M.Weldon@gre.ac.uk or Sharon.Weldon@bartshealth.nhs.uk (Corresponding author)

${ }^{b}$ Barts Health NHS Trust, The Royal London Hospital, Whitechapel Rd, Whitechapel E1 1BB

c Imperial College Centre for Engagement and Simulation Science, Imperial College London, Dept. Surgery \& Cancer, 369 Fulham Rd, Chelsea, London, UK

d University College London, Institute of Education, 20 Bedford Way, Bloomsbury, London, UK

e Centre for Performance Science, Royal College of Music, Prince Consort Road, London, UK

$\mathrm{f}$ Tulane Center for Advanced Medical Simulation \& Team Training, Tulane University School of Medicine, 1430 Tulane Ave, New Orleans, LA, USA

g Stanford University, Department of Surgery, 300 Pasteur Dr H3591 Stanford, CA, USA

Declaration of conflict of interests: None

Key words: Simulation; Communication; Teamwork; Video-Debrief 


\section{Abstract}

\section{Background}

Team communication in operating rooms is problematic worldwide, and can negatively impact patient safety. Although initiatives such as the World Health Organization's Surgical Safety Checklist have been introduced to improve communication, patient safety continues to be compromised globally, warranting the development of new interventions. Video-based social science methods have contributed to the study of communication in UK ORs through actual observations of surgical teams in practice. Drawing on this, the authors have developed a surgical team simulation-training model (ViSIOT $\left.{ }^{\mathrm{TM}}\right)$. A proof-of-concept study was conducted in the UK and USA to assess if the ViSIOT $^{\mathrm{TM}}$ simulation-training has applicability and acceptability beyond the UK.

\section{Methods}

ViSIOT $^{\mathrm{TM}}$ training was conducted at two simulation centers in the UK and USA over a 10-month period. All surgical team participants completed a questionnaire (that assessed design, education, satisfaction and self-confidence in relation to the training). Descriptive and inferential statistics were performed for the quantitative data and thematic analysis was conducted for the qualitative data.

\section{Results}

There was strong agreement from all participants in terms of their perception of the course across all sub-sections measured. Nine themes from the qualitative data were identified. The two countries shared most themes, however, some emerged that were unique to each country.

\section{Conclusions}

Practical developments in the course design, technology and recruitment were identified. Evidence of the course applicability in the USA provides further affirmation of the universal need for team communication training within ORs. Further studies are required to assess its effectiveness in improving communication in OR practice. 
Running Head: VISIOT ${ }^{\text {TM }}$ PROOF-OF-CONCEPT STUDY

ACGME core competencies addressed: Interpersonal and Communication Skills; Practice-Based Learning and Improvement 
Running Head: VISIOT ${ }^{\mathrm{TM}}$ PROOF-OF-CONCEPT STUDY

\section{Introduction}

Team communication in the operating room (OR) appears to be problematic worldwide. ${ }^{1,2}$ Most errors and near-misses in surgery that have the potential to cause harm to patients have been traced back to communication highlighting clinicians' non-technical skills as critically important. ${ }^{3}$ Even though improvements, such as the World Health Organization's (WHO) Surgical Safety Checklist have been introduced to ORs, patient safety continues to be compromised globally, warranting the development of new interventions. ${ }^{4,5}$ To improve patient outcomes and the safety of surgical patients, teamwork, communication, and working environments require urgent attention. ${ }^{6,7,8}$ However, most interventions aimed at addressing communication practices in ORs have been based on clinician's personal beliefs, opinions and experiences of what the problems are. While these can provide valuable insight into what clinicians believe are causing their difficulties, self-reported methods do not capture what actually happens in the ORs. ${ }^{9,10}$ To date, limited research has been done on actual observations of communication in ORs. Existing studies have often measured predetermined instances of communication using checklists rather than exploring the issues and considering what is happening in detail. ${ }^{11} \mathrm{~A}$ systematic literature review by Weldon et al. ${ }^{12}$ found that of the small number of observational studies undertaken in ORs (26 at time of writing), only a few were published in health-related journals (14), and even fewer in surgical journals (5). Thus, potential learning from such research might not even reach the appropriate population. Video-based social science methods can specifically contribute to the study of communication in clinical settings, ${ }^{13}$ and the present authors have employed these both in research and in the development of simulation training for OR teams.

\section{Surgical Team Simulation Training}

In a recent paper, Cook et al. ${ }^{14}$ called for increased attention to the training of health care teams through simulation-based education. Video-Supported Simulation of Interactions in the Operating 
Running Head: VISIOT ${ }^{\mathrm{TM}}$ PROOF-OF-CONCEPT STUDY

Theatre $\left(\mathrm{ViSIOT}^{\mathrm{T}}\right)$ is a surgical team simulation-training programme based on the empirical findings of a video-based ethnographic project that examined communication in UK ORs. ${ }^{12,13,15-21}$

The training model uses a surgical team simulation, followed by a debrief that incorporates real footage from UK operating theaters (obtained through the original observational study), to highlight instances of communication that impairs functional and seamless working practices. This is an essential and intentional part of the training. Typical methods of simulation debriefing are to re-play video footage of the simulation undertaken by the team in order to reflect on their practice within the simulation. However, there are several specific benefits to utilizing real-life videos instead of replaying simulated practice, such as: participants too often are distracted by watching and drawing observations from their own practice; removing concerns of assigning blame for issues since the current participants are not in the videos; preserving psychological safety for current participants; demonstrating wider applicability of the issues; and removing the possible excuse of ‘ would never do that in a real case'.22

The teams participating in the training are invited to strategize better communication techniques while observing the original observational video footage, followed by a second simulation where they implement these strategies as a form of experiential learning. ${ }^{21}$ This approach draws on Kolb's cyclical model of experiential learning: Stage 1: concrete experience: initial surgical team simulation. Stage 2: observation and reflection: authentic OR video-based debrief. Stage 3: forming abstract concepts: strategizing better communication techniques. Stage 4: testing in new situations: second surgical team simulation to implement the new strategies. ${ }^{23,24}$

The simulation scenarios have been designed to reflect authentic communication issues as found in the original research; rather than being hypothetical, they are data-grounded thus increasing fidelity and authenticity of the communication training. The standard scenario used in ViSIOT ${ }^{\mathrm{TM}}$ is undertaken as follows. The surgical procedure performed is a straightforward laparotomy. Participants are briefed on the scenario (Box 1), and the set-up is within a high-fidelity environment 
Running Head: VISIOT ${ }^{\mathrm{TM}}$ PROOF-OF-CONCEPT STUDY

(Figure 1). However, during the procedure, confederates (a junior surgeon and a circulator) are assigned (through an initial briefing and an ear piece) to recreate the conditions regularly seen within the original observational research. These include: turning the volume of music up, unattaching the suction tubing, misplacing lap pads, needles and instruments, and requesting arbitrary or uncommon instrument names. All these actions would initiate certain responses that the researchers were familiar with seeing in real clinical practice in the original study. Some responses or reactions could create further frustrations and delays due to a lack of appropriate or effective communication.

For example, when a surgeon asked a surgical tech for an instrument by an unfamiliar name, rather than acknowledging the issue with the surgeon directly, techs would often waste time guessing the instrument or asking another team member for help. Another example is when a piece of equipment fails to work, such as the suction machine. Although the 'circulator' (circulating nurse) may be working on the problem, this was often not verbally communicated, leaving the surgeon to guess or verbally request updates on what was happening, or require them to divert their attention from the procedure to visually determine the status of the equipment. Although seemingly mundane, these issues would build to cause increased tensions and frustrations within the teams. Within the simulation, once these issues have been identified, the reactions are monitored by the simulation research team behind a one-way mirror, taking notes and being responsive to any sudden changes in the scenario that would need rectifying to keep on track.

Piloting the training in UK hospitals as a half-day training course has been received well by the OR teams. However, since communication issues are experienced globally, it has been important to pilot the training beyond the UK to investigate whether such issues are recognized in other countries, and whether the training could have universal applicability. In the USA alone, medical errors and mishaps during surgery represent the third leading cause of death after cancer and heart disease ${ }^{25}$ which suggests that communication improvements could have major benefits. The authors piloted the 
Running Head: VISIOT ${ }^{\mathrm{TM}}$ PROOF-OF-CONCEPT STUDY

$\mathrm{ViSIOT}^{\mathrm{TM}}$ training in collaboration with a healthcare institution in a medium-sized Southern city to investigate OR team's responsiveness to the training in the USA context.

Before ViSIOT ${ }^{\mathrm{TM}}$ training could be transferred to the USA; it was necessary to scope any differences between operating room practices in the UK and USA. Roundtable discussions and pilot sessions with US-based OR staff enabled the identification of system, language and staffing differences (Table 1 highlights the main differences identified between countries). Once such differences were identified, it was possible to adapt the sessions to suit USA OR teams whilst still maintaining the original principles of the training.

\section{BOX 1. CASE SCENARIO}

TABLE 1. UK AND USA DIFFERENCES

FIGURE 1. HIGH-FIDELITY SIMULATED SET-UP

\section{Research approach}

A proof-of-concept strategy was employed to determine if this empirically driven simulation model encountered any difference in how the training is received in the USA compared to the UK and to collect preliminary evidence that would inform the development of the model and larger future studies. US and UK OR teams participated in a training session (simulation scenario 1, debriefing, and simulation scenario 2) and completed a questionnaire about their responsiveness to the training (see methods section).

The three main questions addressed were:

1. What is the response to the training in terms of design, educational content, satisfaction and self-confidence, and how important is each aspect to participants (UK \& USA participants).

2. Are there any differences between professions in how the training is responded to?

3. Are there any differences between countries (UK \& USA) in how the training is responded to? 


\section{Methods}

\section{Ethics Statement}

Ethical approval was obtained from the Institute of Education Research Ethics Committee (Reference: REC 647). Informed written consent was obtained from all participants.

\section{Sample}

A convenience sample was obtained due to different but similar difficulties experienced in forming surgical teams for training in both countries. In the UK, surgical simulation training is predominantly undertaken and financed within hospital grounds. Therefore, the UK sessions were undertaken in an urban hospital (participants were assigned by the theater manager to attend in their existing specialty focused teams). In the USA, surgical simulations are predominantly undertaken in simulation centers which exist to serve and are financed by their own sponsoring institution, both academic and hospital based. Therefore, each individual center generally serves only their own community. Opportunities to participate in surgical simulation, for USA healthcare professionals not affiliated with a simulation program, are limited. Therefore, the USA sessions were undertaken in an urban simulation center that recruited surgical professionals through voluntary reimbursed means to create surgical teams.

\section{Instruments}

In order to address the research questions, a combination of the Simulation Design Scale (SDS), Educational Practice's Questionnaire (EPQ) and the Student Satisfaction and Self-Confidence in Learning Scale (SCLS) ${ }^{26,27}$ were combined and modified for the purpose of the study (see Appendix A). All three instruments had validity evidence based on content and reliability $(0.92-0.96 ; 0.86-0.91$; 0.87-0.94, respectively) as individual instruments. However, due to necessary modifications being conducted, further reliability testing was required. 


\section{Analysis}

\section{Reliability of modified instrument}

The questionnaire used (Appendix A) was made up of the three separate questionnaires with substantial validity evidence (SDS; EPQ; SCLS) and modified for purpose, therefore, a reliability analysis using Cronbach's analysis was conducted. This not only tested the internal reliability of the questions but also allowed for adjustments to be made that would improve the validity evidence (e.g. in some circumstances removing an item would raise the alpha).

\section{Quantitative}

IBM SPSS Version $21.0^{28}$ was used to generate descriptive statistics (Means and Standard Deviations) of the overall perception of the training and its importance to the participants in terms of design, educational content, satisfaction and self-confidence.

A Wilcoxon Signed Ranks Test was conducted to compare two related samples ( ${ }^{\mathrm{a}} \mathrm{a}^{\mathrm{b}}$ questions) on a single sample to assess whether their mean ranks differed in terms of their perception ( ${ }^{a}$ questions) of the course and how important that was to them ( ${ }^{b}$ questions). An Exact Test was performed due to the small sample size to generate an exact P-value.

Mann-Whitney U Tests were performed to look at the differences between the professional's scores ( ${ }^{a}$ questions only). Due to the differences in professional roles across countries, professional roles were grouped into categories relating to their tasks: surgeons; anesthetics (anesthesiologists, CRNA and ODPs); Nursing (RGNs, RNs, and scrub techs). Further Mann-Whitney U Test's tested if there were any differences in scoring between UK and USA participants.

\section{Qualitative}

An inductive thematic analysis employing NVivo qualitative data analysis software ${ }^{29}$ was conducted for the questionnaires open-ended feedback section termed 'further comments'. Analysis was 
Running Head: VISIOT ${ }^{\mathrm{TM}}$ PROOF-OF-CONCEPT STUDY

performed separately for each country (UK, USA) to identify any differences in participant's experiences, perceptions or attitudes towards the course not captured in the closed questions.

\section{Results}

A total of eight surgical simulation courses were run ( 2 X UK, 6 X USA) between December 2016 and September 2017, and 37 participants were recruited to the study: 9 surgeons ( 3 UK; 6 USA), 14 RGN's (7 UK; 7 USA), 8 anesthesiologists (2 UK; 6 USA), 5 Scrub Techs, and 1 ODP.

Reliability analysis

A Cronbach's analysis was conducted on the 'Course objectives and information' subscale of the questionnaire (questions 1-4). Alpha level = .71 (High reliability. Good internal item reliability) which indicated that the subscale had an adequate level of inter-item reliability.

For the 'Simulation activity' subscale of the questionnaire (questions 5-7). Alpha level $=.55$, which indicated that the subscale did not have an adequate level of inter-item reliability. However, further analyses revealed that by deleting the item 'Using simulation activities made my learning time more productive', the alpha could be raised to .65 , although this was still below the .7 benchmark required for good inter-item reliability. Therefore, it was found that deleting any of the items would not significantly increase the alpha level.

For the 'Simulation fidelity' subscale of the questionnaire (questions 8-9). Alpha level $=.59$, which indicated that the subscale did not have an adequate level of inter-item reliability. However, when combining 'simulation activities' and 'simulation fidelity' as a subscale termed 'simulation' (questions 5-9) the alpha level $=.7$ was raised. This approach also made logical sense regarding the subsections focus.

For the 'Debrief' subscale of the questionnaire (questions 10-13). Alpha level $=.63$, which indicated that the subscale did not have an adequate level of inter-item reliability. However, analyses revealed that by deleting the item 'The simulation and videos allowed me to analyse my behavior and 
Running Head: VISIOT ${ }^{\mathrm{TM}}$ PROOF-OF-CONCEPT STUDY

actions', the alpha could be raised to .72 . This is probably due to the videos being of other's actions and not of the participants watching themselves in the simulation.

For the 'Course evaluation' subscale of the questionnaire (questions 14-18). Alpha level $=.67$, which indicated that the subscale did not have an adequate level of inter-item reliability. However, analyses revealed that by deleting the item 'The course provided me with a variety of learning materials and activities to promote my learning', the alpha could be raised to .75 .

\section{Quantitative results}

Tables 2 displays the mean and Standard Deviation (SD) for each sub-set of the questionnaire (course objectives, simulation activity, debrief, and course evaluation). Questions are divided by ${ }^{\text {a }}$ and ${ }^{b}$, with ${ }^{a}$ referring to the participant's perception of the course on the day and ${ }^{b}$ referring to how important that is to them in general. Means and SDs are also calculated for the sub-set as a scale, and $p$-values are calculated for each subset to determine any differences between perception and importance.

All questions had a mean score of between 4.30 and 4.84 indicating a strong agreement in terms of the participant's perception of the course across all sub-sections. Scale means were between 4.60 and 4.76. There was two significant $p$-values $(<0.05)$ in relation to the difference between perception and its importance to the participant and this was for the debrief and course evaluation sub-scales. Only one professional comparison (Surgeons and Anesthetists) had a significant $p$-value $(<0.05)$ in terms of the differences in perception of the simulation activity (Table 3$)$. A difference $(<0.05)$ in perception of the simulation activity was then replicated between the UK and USA participants (Table 4).

TABLE 2. OVERALL PERCETOPTION OF THE TRAINING FOR EACH SUB-SET OF THE QUESTIONNAIRE TABLE 3. MANN-WhitNEY U TEST'S FOR DIFFERENCES BETWEEN THE PROFESSIONAL'S SCORES (a QUESTIONS ONLY) TABle 4. MANn-Whitney U TeSt’S FOR DifFERENCES BETWEEN UK AND USA SCORES ( ${ }^{\mathrm{a}}$ QUESTIONS ONLY) 


\section{Qualitative results}

A total of 9 themes were identified from both the UK and USA (Figure 2). Though the two countries shared most themes, some emerged that highlighted areas of key differences that were unique to each country. Shared themes included 'video' in relation to the video material used; 'fidelity' in relation to the realism of the simulation; 'development' in relation to improvements that could be made to the course; praise in relation to how they felt about the course. However, the UK pilots generated themes that were unique to the UK setting such as 'missing professionals' and the course 'not [being] applicable'. The USA pilot themes generated focused on the 'course content', 'practice reflection' and 'UK and USA comparisons'. The following categories discuss the themes in more detail.

FIGURE 2. THEMES FROM BOTH UK \& USA PILOTS

UK and USA matched themes

'Video'

The 'Video' theme was the largest for both countries and highlighted the importance of the videos to the training. One UK participant stated, 'The videos were helpful because they reflect some real situations, how we work and what actually happens in the environment' [UK-RGN]. A USA participant stated 'watching the videos enlightened me to how we could improve our particular aspects of communication in the OR. I could see some of the mistakes are common and how improvement is important for more positive outcomes and work environment' [USA - RN]. Others from the USA focused on what the videos enabled 'the compare and contrast of the different ORs (videos) was an equalizer' [Surgical Tech] and 'videos showed great examples of the errors and issues of OR communication and helped the discussion about ways to improve it' [USA Anesthesiologist]. However, a few commented on the quality of the video 'the only thing I would improve upon is the video quality. Other than that, I think it would be great for everyone to 
Running Head: VISIOT ${ }^{\mathrm{TM}}$ PROOF-OF-CONCEPT STUDY

participate in' [USA - Anesthesiologist] and another noted 'I couldn't hear the audio very well on the videos but possibly that was a teaching point!' [USA - Surgical Tech] - This last comment could be in relation to the videos showing communication whilst music was being played.

\section{'Praise'}

The second largest theme was based around praise for the training course. One UK participant stated 'Excellent course. Advertise/promote this at [anonymized hospital name]. Manager told me about this three days ago - no one else knew. Surgeons would find this very interesting and helpful' [UK - Surgeon]. Another US participant praised its importance 'No one at [censored] ever gets the opportunity to have conversations about how the OR runs in inter-professional groups, unless it's after a critical error happens. Otherwise there are never discussions and little understanding of each other's roles' [USA - Surgical Tech].

\section{'Fidelity'}

The theme 'Fidelity' was the third largest thematic category and was split between those who described the simulation as being very realistic 'the simulation was very realistic and it was easy to allow "willing suspension of disbelief"' [USA - Anesthesiologist] and 'Really appreciated the simulated patient [laparotomy model]. This provided an opportunity to simulate the experience of a real-life situation quite well' [USA - Surgeon]. However, others provided feedback to make the simulation more realistic 'Maybe provide more instruments or equipment needed as seems more real. Maybe start with cleaning and draping and the step for the WHO checklist' [UK - RGN] and 'to assess the suction you should have more bleeding. I didn't need to use it and didn't even notice when it went off' [USA - Surgeon\} as well as 'the biggest challenge was being unfamiliar with the manikin, otherwise the scenarios were realistic and a good learning tool' [USA - Surgeon].

\section{'Development'}

The final joint theme 'Development' highlighted by both countries suggested improvements to different components of the course. Some participants focused on the debrief and videos, 
suggesting 'Would it be useful to use some of the film footage to reflect on behaviours witnessed? It might be useful to see differences between perceived and actual behaviours' [UK - Surgeon] and 'emphasising at the beginning that the focus of the course is on communication and redirecting group members who go off topic' [USA - Anesthesiologist]. Alternatively, other participants focused on the improvements to the simulation with one participant stating, 'provide a little more clarity during the simulation case as to when the 'case' is actually starting' [USA - Surgeon] and 'a little more guidance in terms of what I should do in terms of giving drugs or making adjustments on the anesthetic machine' [USA - Anesthesiologist]

\section{UK specific themes}

\section{'Missing professions'}

In the UK, there was an issue on one of the courses in recruiting surgeons to attend, instead a trainee surgeon working within the PI's research group took the role of the surgeon to ensure the course could go ahead. The staff that did attend highlighted this 'I'm sorry that no surgeon was in the study group' [RGN] and 'Have more surgeons involved in the discussion' [Surgeon].

\section{'Not applicable'}

Because the participating NHS hospital oversaw recruiting the teams to attend, there was at times a misalignment in who that should be as noted by one participant 'Honestly, I don't think these sessions are made for recovery nurses, because all the discussions are about what happened inside the theaters and I don't work there' $[R G N]$.

\section{USA specific themes}

\section{'Course content'}

There was a lot of reflection by the USA participants on the course content with one participant writing 'We got to discuss issues that repeatedly occur in the OR and aren't usually addressed appropriately. Moreover, we got to appreciate different points of view and reactions to the same 
situation based on our current roles in the OR. I think it definitely made me more aware of situations and uncomfortable/unsuitable situations that can be easily remedied and fixed. I would make the course a good part of any training programme for professionals working in the OR. Above all, it was a lot of fun!' [Surgeon] and 'The course demonstrated several things that I never realised could be clinically important in the OR and resulted in solutions' [Anesthesiologist]. A particular emphasis was on the multidisciplinary nature of the course 'I enjoyed having all participants of the OR team involved. It allowed me to see the experience through their eyes' [Surgical Tech] and 'More verbal immediate response between the team in the OR during the second simulation. I found it very necessary and helpful' [Surgical Tech]. Others focused on what was discussed 'The discussion on music in the OR was very relevant' [Anesthesiologist] and 'The discussion following the simulation allowed for reflection of our performance and made it more meaningful' [Anesthesiologist].

\section{'Practice reflection'}

Importantly, participants in the USA linked the course to their own practice with one participant recognising the courses applicability to their own practice by stating 'Every case in the ORs I have worked in lack different opinions and have poor communication - bullying - and lack of ethics' $[R N]$ and others stating how they will take their learning from the course forward 'I think the experience will allow me to self-analyse and be situationally aware in the real world' [Surgeon] and 'Great experience, will be valuable to my career moving forward' [Surgical Tech].

\section{'UK and USA comparisons'}

The majority of participants saw the UK-based video's as useful due to 'The culture and professions are similar and we can learn from one another' [Surgical Tech] and 'Not knowing some of the terminology levelled the field to put yourself in the situation' [Surgical Tech] as well as 'It is very interesting to see UK based ORs have similarities' $[R N]$. However, one participant identified the differences in terms of the presence of UK separate (induction and prep) rooms and their impact on 
Running Head: VISIOT ${ }^{\mathrm{TM}}$ PROOF-OF-CONCEPT STUDY

the WHO checklist 'I found that there are some shocking differences between how things are done in the UK compared to the US' [Surgical Tech].

\section{Discussion}

All aspects of the course were highly rated with participants agreeing and strongly agreeing with the statements in the questionnaires. The majority of participants also felt that most of the statements in the question were important to them in terms of what they expect from a course. However, there was a difference in terms of the course evaluation statements and its importance to participants with scores indicating that participants were not so concerned about debriefing and whether the course was enjoyable and used appropriate materials and approaches to facilitate learning. This suggests that the participants were more interested in what happens than how it happens, perhaps reflecting that details such as debriefing, materials and learning were handled appropriately and therefore unproblematic, or alternatively a lack of understanding from an educational perspective on how learning is facilitated.

There were significant differences between the simulation activity responses of surgeons and anesthesiologists and between the UK and USA; however, all means were above 4 indicating a strong agreement regardless.

The videos used for the course are from empirical observations of real operating rooms and are a unique aspect of this training course and a crucial stage in the learning process. It was therefore encouraging to see this theme positively emerge the most within the qualitative data across both countries, highlighting its importance within the course. However, it is clear that auditory and visual improvements are required to ensure they are utilized clearly and effectively. Therefore, investing in professional editing, audio improvements, and sub-titling would improve the course and its potential beneficial effects in the long run. 
Running Head: VISIOT ${ }^{\mathrm{TM}}$ PROOF-OF-CONCEPT STUDY

It was also encouraging to receive so much praise for the course across both countries. However, differences amongst participants (not based on country or profession) were seen regarding the fidelity of the simulation. This could be due to differences during each pilot conducted or differences in expectations and experiences of simulation. This is certainly a discrepancy that needs to be addressed to ensure an optimal and realistic experience for all to enhance the learning and transferability to real practice. The development theme was highly useful in providing practical examples of how to address some of courses issues in order to improve it.

Within the UK context, issues related to participant recruitment were highlighted and identified a need for course facilitators to have more of a role in terms of who is recruited and the advertising/communication processes. Based on the existing simulation experience of the USA partner, we anticipate similar recruiting issues and a similar need to tighten course facilitation and recruitment to ensure appropriate teams and expectations are addressed.

Within the USA context, proof-of-concept and applicability of the course was demonstrated through the valuable comments made on the course content, practice reflection and beneficial UK and USA comparisons. Participants from the USA provided rich descriptions of how and why the course was beneficial to them in their own context.

\section{Limitations}

Due to the difficulties in recruitment within the UK context, only two simulations were run compared to the six anticipated. However, as the model has been effectively used in the UK previously and is based on UK OR data, it was deemed more important to achieve the USA simulation scenarios. The sample size was not large and only conducted in one institution in each country; however, as this study aimed to demonstrate proof-of-concept rather than show generalizability, it was deemed sufficient for the needs of the study. 
Running Head: VISIOT ${ }^{\mathrm{TM}}$ PROOF-OF-CONCEPT STUDY

\section{Conclusion}

Practical developments in the course design, technology and recruitment considerations were identified. These nuances are extremely important in the development of any sophisticated and highly complex training course and will provide the next iterative step in refinement and improvement. Evidence of the course applicability in the USA provides further affirmation of the universal need for communication and team training within operating rooms. Evaluation of system, language and staffing differences must be performed prior to utilization of the training course in a new healthcare delivery system.

Further studies are required to assess its effectiveness in improving teamwork and communication in OR practice, as well as any potential benefit to patient outcomes. In order to achieve this, a wider systematic adoption of the training, over a larger geographical area is required. In line with this, the authors have obtained further funding to expand the training programme and its potential users. Therefore, the next steps are to develop a comprehensive training resource (based on the findings to date) that will enable a broader, and more systematic implementation of the training. The videos will be edited to include voice-overs that will ensure a higher quality of sound and geographically appropriate language.

\section{Acknowledgements}

The development of $\mathrm{ViSIOT}{ }^{\mathrm{TM}}$ and the independent research projects tied in with its development have received support from a range of funders: Economic and Social Research Council Impact Acceleration Award (Ref: ES/M500562/1), British Academy (Ref: SG161260) (Ref: PF140002), University College London Sea and Currents Funding (Ref:156780). In-kind support has been provided by Tulane Centre for Advanced Medical Simulation and Team Training and Chelsea and Westminster Hospital NHS Trust. 


\section{References}

1. Attri JP, Sandhu GK, Mohan B, Bala N, Sandhu KS, Bansal L. Conflicts in operating room: Focus on causes and resolution. Saudi J Anaesth 2015;9(4):457-463. Doi: 10.4103/1658$354 X .159476$

2. Halverson AL, Casey JT, Andersson J, Anderson K, Park C, Rademaker AW, Moorman D. Communication failure in the operating room. SURGERY 2011;149(3);305-310.

3. Caprice CK, Gustafson ML, Roth EM, Sheridan TB, Ghandi TK, Dwyer K, et al. A prospective study of patient safety in the operating room. SURGERY 2006; 139(2);159-173.

\section{https://doi.org/10.1016/j.surg.2005.07.037}

4. Gillespie B, Marshall A. Implementation of safety checklists in surgery: a realist synthesis of evidence. Implementation Science 2015;10(1);137

5. Korkiakangas T. Mobilising a team for the WHO Surgical Safety Checklist: a qualitative video study. BMJ Qual Saf 2017;26:177-188.

6. Tschan F, Seelandt JC, Keller S, Semmer NK, Kurmann A, Candinas D, et al. Impact of caserelevant and case-irrelevant communication within the surgical team on surgical-site infection. British Journal of Surgery 2015;102;1718-1725 DOI: 10.1002/bjs.9927.

7. Lingard L, Regehr G, Cartmill C, et al. Evaluation of a preoperative team briefing: a new communication routine results in improved clinical practice. BMJ Qual Saf 2011;20:475-482.

8. Gardezi F, Lingard L, Espin S, Whyte S, Orser B, Baker GR. Silence, power and communication in the operating room. Journal of Advanced Nursing 2009;65(7);1390-1399.

9. Walker JD. Communication in the Cardiac Operating Room: A Surgeon's Perspective. Journal of the American Society of Echocardiography 2010;23(10); A21-A21

10. Nestel D, Kidd J. Nurses' perceptions and experiences of communication in the operating theatre: a focus group interview. BMC Nursing2006;5:1 https://doi.org/10.1186/1472-6955$5-1$

11. Undre S, Sevdalis N, Healey A, Darzi A, Vincent C. Observational Teamwork Assessment for Surgery (OTAS): Refinement and Application in Urological Surgery. World J Surg 2007;31: 1373. https://doi.org/10.1007/s00268-007-9053-z

12. Weldon SM, Korkiakangas T, Bezemer J, Kneebone R. Communication in the operating theatre: A systematic literature review of observational research. British Journal of Surgery 2013;100(13);1677-1688

13. Bezemer J, Cope A, Korkiakangas T, Kress G, Murtagh G, Weldon SM, Kneebone R. Microanalysis of video from the operating room: an underused approach to patient safety research. BMJ Quality and Safety 2016;1-5. 
14. Cook DA, Anderson DK, Combes JR, Feldman DL, Sachdeva AK. The value proposition of simulation-based education. SURGERY 2017;163(4);944 - 949. DOI: https://doi.org/10.1016/j.surg.2017.11.008

15. Bezemer J, Korkiakangas T, Weldon SM, Kress G, Kneebone R. Unsettled teamwork: Communication and learning in the operating theatres of an urban hospital. Journal of Advanced Nursing2015;72(2);361-372. http://dx.doi.org/10.1111/jan.12835

16. Korkiakangas T, Weldon S., Bezemer J, Kneebone R. Nurse-surgeon object transfer: Video analysis of communication and situation awareness in the operating theatre. International Journal of Nursing Studies 2014;51(9);1195-1206.

http://dx.doi.org/10.1016/j.ijnurstu.2014.01.007

17. Korkiakangas T, Weldon SM, Bezemer J, Kneebone R. “Coming Up!”: Why verbal acknowledgement matters in the operating theatre. In S. White \& J. Cartmill (Eds.), Communication in Surgical Practice. Equinox; 2016

18. Weldon SM, Korkiakangas T, Bezemer J, Kneebone R. Music and communication in the operating theatre. Journal of Advanced Nursing 2015;71(12);2763-2774. http://dx.doi.org/10.1111/jan.12744

19. Weldon SM, Korkiakangas T, Bezemer J, Kneebone R, Kress, G, Nicholson, K. Video Analysis of Bodily Conduct in Teamwork within the Operating Theatre. INTERNATIONAL JOURNAL OF QUALITATIVE METHODS 2012;11;895-896

20. Weldon SM, Korkiakangas T, Bezemer J, Kneebone R, Nicholson K, Kress G. Transient Teams in the Operating Theatre. The Operating Theatre Journal 2012;261(1);2

21. Korkiakangas T, Weldon, SM, Bezemer J, Kneebone R. Video-supported Simulation for Interactions in the Operating Theatre (ViSIOT). Clinical Simulation in Nursing 2015;11(4);203207

22. Elfrink VL, Nininger J, Rohig L, Lee J. The case for group planning in human patient simulation. Nursing Education Perspectives 2009;30(2);83-86

23. David L. "Experiential Learning (Kolb)". Learning Theories;2007

24. Kolb DA. Experiential learning: Experience as the source of learning and development. FT press;2014

25. Makary MA, Daniel M. Medical error-the third leading cause of death in the US. BMJ: British Medical Journal 2016;353.

26. Franklin AE, Burns P, Lee CS. Psychometric testing on the NLN Student Satisfaction and SelfConfidence in Learning, Simulation Design Scale, and Educational Practices Questionnaire 
Running Head: VISIOT ${ }^{\text {TM }}$ PROOF-OF-CONCEPT STUDY

using a sample of pre-licensure novice nurses. Nurse Educ Today 2014;34(10):1298-304. Doi: 10.1016/j.nedt.2014.06.011. Epub 2014 Jul 9.

27. Unver V, Basak T, Watts P, Gaioso V, Moss J, Tastan S, et al. The reliability and validity of three questionnaires: The Student Satisfaction and Self-Confidence in Learning Scale, Simulation Design Scale, and Educational Practices Questionnaire. Contemp Nurse 2017;53(1):60-74. Doi: 10.1080/10376178.2017.1282319. Epub 2017 Feb 10.

28. IBM Corp. Released 2012. IBM SPSS Statistics for Windows, Version 21.0. Armonk, NY: IBM Corp.

29. NVivo qualitative data analysis Software; QSR International Pty Ltd. Version 10, 2014. 
Appendix A

\section{MisıOT Questionnaire}

In order to measure the ViSIOT course in terms of its design and your learning, please complete the survey below as you perceive it. There are no right or wrong answers, only your perceived amount of agreement or disagreement. Please use the following code to answer the questions.

Please state your profession:

\begin{tabular}{|c|c|c|c|c|c|c|c|c|c|c|c|}
\hline \multicolumn{7}{|c|}{$\begin{array}{l}\text { Use the following rating system when assessing elements related to the ViSLOT course: } \\
\text { 1- Strongly Disagree with the statement } \\
\text { 2- Disagree with the statement } \\
\text { 3- Undecided - you neither agree or disegree with the statement } \\
\text { 4- Agree with the statement } \\
\text { 5- Strongly Agree with the statement } \\
\text { NA - Not Applicable; the statement does not pertain to the simulation activity performed. }\end{array}$} & \multicolumn{5}{|c|}{$\begin{array}{l}\text { Rate each item based upon } \\
\text { how important } \\
\text { that item is to you. } \\
\text { 1- Not Important } \\
\text { 2- Somewhat Important } \\
\text { 3- Neutral } \\
\text { 4- Important } \\
\text { 5- Very Important }\end{array}$} \\
\hline Item & 1 & 2 & 3 & 4 & 5 & N/A & & 7 & 12 & 4 & 5 \\
\hline \multicolumn{12}{|l|}{ Course objectives \& Information } \\
\hline $\begin{array}{l}\text { 1. There was enou } \\
\text { beginning of the si } \\
\text { encouragement. }\end{array}$ & $\mathrm{O}$ & $\mathrm{O}$ & 0 & $\mathrm{O}$ & $\mathrm{O}$ & 0 & $\mathrm{O}$ & 0 & 0 & 0 & $\mathrm{O}$ \\
\hline Idte & 0 & 0 & 0 & $\mathrm{O}$ & 0 & 0 & $\mathrm{O}$ & 0 & 0 & 0 & 0 \\
\hline & 0 & $\mathrm{O}$ & 0 & 0 & $\mathrm{O}$ & 0 & 0 & 0 & 0 & 0 & 0 \\
\hline & $\mathrm{O}$ & $\mathrm{O}$ & 0 & $\mathrm{O}$ & $\mathrm{O}$ & 0 & $\mathrm{O}$ & 0 & 0 & 0 & $\mathrm{O}$ \\
\hline \multicolumn{12}{|l|}{ Simulation activity } \\
\hline 5. Usings & 0 & $\mathrm{O}$ & 0 & $\mathrm{O}$ & $\mathrm{O}$ & 0 & $\mathrm{O}$ & 0 & 0 & 0 & $\mathrm{O}$ \\
\hline $\begin{array}{l}6.1 \mathrm{~h} \\
\text { the s }\end{array}$ & 0 & $\mathrm{O}$ & 0 & $\mathrm{O}$ & $\mathrm{O}$ & 0 & $\mathrm{O}$ & 0 & 0 & 0 & $\mathrm{O}$ \\
\hline & 0 & 0 & 0 & 0 & 0 & 0 & 0 & 0 & 0 & 0 & 0 \\
\hline & 0 & 0 & 0 & 0 & 0 & 0 & $\mathrm{O}$ & 0 & 0 & 0 & טע \\
\hline & 0 & 0 & 0 & 0 & 0 & 0 & 0 & 0 & 0 & 0 & 0 \\
\hline \multicolumn{12}{|l|}{ Debrief } \\
\hline 10. The & 0 & $\mathrm{O}$ & 0 & 0 & $\mathrm{O}$ & 0 & 0 & 0 & 0 & 0 & $\mathrm{O}$ \\
\hline $\begin{array}{l}\text { guid } \\
\text { builc }\end{array}$ & 0 & $\mathrm{O}$ & 0 & 0 & 0 & 0 & $\mathrm{O}$ & 0 & 0 & 0 & $\mathrm{O}$ \\
\hline $\begin{array}{l}12.1 \mathrm{a} \\
\text { sessic }\end{array}$ & $\mathrm{O}$ & 0 & 0 & 0 & 0 & 0 & $U$ & 0 & 0 & 0 & 0 \\
\hline $\begin{array}{l}\text { 13. I had the oppor } \\
\text { my comments durin }\end{array}$ & 0 & 0 & 0 & 0 & 0 & 0 & 0 & 0 & 0 & 0 & $\mathrm{O}$ \\
\hline \multicolumn{12}{|l|}{ Course } \\
\hline 14. T & 0 & 0 & 0 & 0 & 0 & 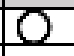 & 0 & 0 & 0 & 0 & 2 \\
\hline $\begin{array}{l}15.7 \\
\text { learr } \\
\text { prom }\end{array}$ & 0 & 0 & 0 & 0 & 0 & 0 & 0 & 0 & 0 & 0 & $\mathrm{O}$ \\
\hline 16. I enjoyed how the & 0 & 0 & 0 & 0 & 0 & 0 & 0 & $\mathrm{O}$ & 0 & 0 & 0 \\
\hline & $\mathrm{O}$ & $\mathrm{O}$ & 0 & 0 & 0 & 0 & $\mathrm{O}$ & 0 & 0 & 0 & $\mathrm{O}$ \\
\hline $\begin{array}{l}\text { 18. The way the course was taught was } \\
\text { the way I leam. }\end{array}$ & 0 & $\mathrm{O}$ & 0 & 0 & 0 & 0 & $\mathrm{O}$ & 0 & 0 & 0 & 0 \\
\hline
\end{tabular}

